\title{
Combined therapy with cisapride and cimetidine in severe reflux oesophagitis: a double blind controlled trial
}

\author{
J P GALMICHE, G BRANDSTÄTTER, M EVREUX, E HENTSCHEL, \\ E KERSTAN, P KRATOCHVIL, W REICHEL, K SCHÜTZE, J C SOULE, \\ AND J VITAUX
}

From the Clinique des maladies de l'appareil digestif, Hôpital Guillaume et René Laennec, Nantes, France, II Med Abteilung, LKH Graz, Graz, Austria, Service d'hépato-gastroentérologie, Hôtel Dieu, Lyon, France, I Med Abteilung, Hanusch-Krankenhaus, Wien, Austria, 4 Med Abteilung, Wilhelminenspital, Wien, Austria, Hôpital Henri Mondor, Créteil, France, and rue d'Astorg, Paris, France

SUMMARY Combined treatment with cimetidine $1 \mathrm{~g}$ daily and cisapride $40 \mathrm{mg}$ daily in patients with endoscopically diagnosed severe reflux oesophagitis was compared with single drug therapy (cimetidine and placebo). At the end of the six to 12 weeks treatment, 11 (46\%) of the 24 patients under single drug therapy were endoscopically healed and three were improved. In contrast, 16 $(70 \%)$ of the 23 patients under combined therapy were healed and all of the remainder were improved $(p=0 \cdot 025)$. The severity of diurnal and nocturnal heartburn, decreased significantly more $(p<0 \cdot 05)$ on cimetidine + cisapride than on cimetidine + placebo. The combined treatment was well tolerated. These results suggest that combined therapy with cisapride and cimetidine may be useful in patients with severe reflux oesophagitis.

Major factors in the pathogenesis of gastrooesophageal reflux disease include the competence of the lower oesophageal sphincter, efficacy of the oesophageal clearance function, irritant effect of refluxed material, and resistance of the oesophageal mucosa. ${ }^{1-3} \mathrm{~A}$ stepwise strategy has been suggested for the treatment of this chronic digestive disorder. ${ }^{45}$ Elevation of the head of the bed, dietary modifications, and the use of antacids seem useful to the majority of patients with mild or intermittent symptoms. Some patients fail to respond to this socalled 'phase-1' therapy, however, and more active pharmacological agents ('phase-2' treatment) are required in order to increase the lower oesophageal sphincter pressure, amplitude of peristaltism, and rate of gastric emptying as well as reduce gastric acid secretion.

Cisapride is a newly developed digestive prokinetic drug $^{6}$ which increases the lower oesophageal

Address for correspondence: J P Galmiche. Clinique des maladies de l'appareil digestif, Hôpital Guillaume et René Laennec. CHU Nord 44035. Nantes, France.

Received for publication 2 November 1987 sphincter pressure and enhances oesophageal acid clearance, thus preventing excessive regurgitation and prolonged exposure of the oesophageal mucosa to refluxed material. Cisapride also promotes gastric emptying of both solids and liquids ${ }^{7}$ and reduces duodenogastric bile reflux. ${ }^{8}$ Although cisapride has indirect cholinomimetic effects, it does not affect gastric acid output. ${ }^{9}$ When compared with placebo, the drug has been shown to be effective in the treatment of gastro-oesophageal reflux with regard to symptomatic relief and healing of mucosal lesions. ${ }^{10}$

The efficacy of $\mathrm{H}_{2}$-blockers in peptic oesophagitis is well established but the benefit of combined therapy using cimetidine and prokinetic drugs such as metoclopramide is still a matter of debate; conflicting results have been reported. ${ }^{112}$ This prompted us to evaluate the possible benefit of combined therapy with cisapride+cimetidine in patients with severe reflux oesophagitis. Our primary aim was to assess the healing rate of endoscopic lesions after single drug therapy (cimetidine+placebo) and after combined therapy (cimetidine + cisapride); our secondary aim was to study symptom relief during both 
treatments. In this paper, we report the results of a double blind, controlled, randomised multicentre study conducted in France and Austria.

\section{Methods}

\section{PATIENTS}

Adult outpatients were included in the study if they had endoscopically diagnosed Savary-Miller grade II (longitudinal erosive or ulcerative mucosal confluent defects) or III (circular lesions) oesophagitis. ${ }^{13}$ Exclusion criteria were pregnancy, intestinal obstruction, gastrointestinal malignancy, previous gastrointestinal surgery, non-digestive diseases, inability to express subjective complaints, or excessive alcohol consumption. Patients receiving anticholinergics, cholinergics, gastrokinetics, neuroleptics, antiemetics, $\mathrm{H}_{2}$-blockers, or sucralfate were also excluded.

Forty nine patients were selected and gave informed consent to participate in the study. Two patients could not be evaluated and were excluded from analysis, one because of non-compliance with the medication, and another because control endoscopy was refused.

The characteristics of the patients in the 2 study groups are summarised in Table 1. Endoscopy showed severe oesophagitis in all 47 patients and Barrett's oesophagus in one case. Heartburn was the predominant symptom. Regurgitation of gastric con-

Table 1 Patient characteristics at selection

\begin{tabular}{lll}
\hline & $\begin{array}{l}\text { Cisapride+ } \\
\text { cimetidine }\end{array}$ & $\begin{array}{l}\text { Placebo+ } \\
\text { cimetidine }\end{array}$ \\
\hline Patients (male, female) (n) & $23(19,4)$ & $24(20,4)$ \\
Age (yr) & $56(15)$ & $55(15)$ \\
Non-smokers non-drinkers & 10 & 11 \\
Smokers or drinkers & 8 & 10 \\
Smokers and drinkers & 4 & 3 \\
Oesophagitis grade III & 6 & 6 \\
\multicolumn{1}{c}{ grade II } & 17 & 18 \\
Heartburn (incl. 1 Barrett’s) & \\
Regurgitation & 19 day, 17 night & 21 day, 21 night \\
& 11 day, 11 night & 15 day, 18 night \\
\hline
\end{tabular}

No significant intergroup differences, except for night time regurgitation $(\mathrm{p}=0 \cdot 02)$. Values are expressed as mean $(\mathrm{SD})$. tents occurred less frequently. Most patients had been taking antacids before entering the trial.

STUDY DESIGN

The patients were randomly allocated to treatment with placebo (PLAC) or cisapride (CIS), $10 \mathrm{mg}$ qid, combined with cimetidine (CIM), $200 \mathrm{mg}$ before each meal, and $400 \mathrm{mg}$ at bedtime. At selection, they were instructed on the usual antireflux measures, mainly elevation of the head of the bed and dietary changes. All patients first completed a one week placebo run in period after which symptoms were assessed and an endoscopy carried out. Thereafter, the patients entered the double blind treatment period. After six weeks, a control endoscopy was done; patients still having oesophagitis continued the study for another six weeks. Throughout the trial, concomitant use of up to four tablets of Maalox ${ }^{\circledR}$ daily was allowed as rescue medication. The study was conducted in accordance with the principles of the declaration of Helsinki.

\section{ASSESSMENTS}

Endoscopy was done at the end of the run in period and after weeks six and 12 (if treatment was continued) of the double blind treatment period. Friability, exudation, erosion, or ulceration of the oesophageal mucosa were assessed. The rating system for these five parameters is given in Table 2 . In addition, a global assessment was made of the endoscopic changes: healing was defined as the disappearance of ulcers and/or erosions, and improvement as either disappearance of a previous ulcer or a decrease of the initial Savary-Miller grade. At the start and after six and/or 12 weeks of treatment, both night time and daytime symptoms were evaluated by the investigator and scored on four point rating scales. The severity of heartburn was rated severe (disabling pain or pain occurring at night and causing awakening), moderate (tolerable but refractory to antacids), mild (relieved by antacid intake) or absent. The frequency of regurgitation was graded either as very often ( $\geq 3$ times daily; every night), often (1-2 times daily; 3-6 nights weekly), occasionally (not every day; $<3$ nights weekly).

Patients were asked to record the frequency of

Table 2 Severity ratings for endoscopic parameters

\begin{tabular}{|c|c|c|c|c|}
\hline Rating & Erosions & Ulceration & Exudate & Friability \\
\hline 0 & Absent & Absent & Absent & Absent \\
\hline 1 & Dispersed over $<3 \mathrm{~cm}$ & 1 ulcer $\varnothing<3 \mathrm{~cm}$ & Over $<3 \mathrm{~cm}$ & Bleeding elicited over $<3 \mathrm{~cm}$ \\
\hline 2 & Dispersed over $>3 \mathrm{~cm}$ not confluent & 1 ulcer $\varnothing>3 \mathrm{~cm}$ or more ulcers & Dispersed over $>3 \mathrm{~cm}$ & $\begin{array}{l}\text { Bleeding elicited over }>3 \mathrm{~cm} \\
\text { or blood present over }<3 \mathrm{~cm}\end{array}$ \\
\hline 3 & $\begin{array}{l}>4 \text { lesions, or }<4 \text { lesions but } \\
\text { dispersed over }>3 \mathrm{~cm} \text { and confluent }\end{array}$ & $>1$ ulcer, and 1 with $\varnothing>3 \mathrm{~cm}$ & Confluent over $>3 \mathrm{~cm}$ & Blood present over $>3 \mathrm{~cm}$ \\
\hline
\end{tabular}


heartburn and regurgitations, day and night, and the use of antacids (Maalox ${ }^{\circledR}$, acid neutralising capacity: $25 \mathrm{mmol} / \mathrm{tablet}$ ) on diary cards. At the end of the double blind trial, patients and investigators globally rated the symptomatic response to therapy either as excellent (complete relief of symptoms), good (only occasional symptoms), fair (slight improvement), poor (no clear cut change) or deteriorated.

STATISTICAL ANALYSIS

Intergroup differences in endoscopic and clinical parameters were analysed using the Mann-Whitney U-test, and intragroup changes using the Wilcoxon's matched pairs, signed-ranks test. ${ }^{14}$ Two tailed $p$ values were calculated.

The diary records of weekly Maalox ${ }^{\circledR}$ consumption, and frequency of heartburn and regurgitation, daytime and night time, were combined into a ridit that is, a non-arbitrary weight according to Bross. ${ }^{15}$ Ridits were subjected to a two-way analysis of variance, the two variables being medication groups and time in the study. The explained variation was further subdivided into its components ${ }^{16}$ without any preferential order. ${ }^{17}$ The size of samples required was calculated according to an expected $30 \%$ difference in the healing rate between both treatments (50\% and $80 \%$ for cimetidine and cimetidine plus cisapride, respectively), a risk of $5 \%$, and a $\beta$-risk of $20 \%$ (38 patients in each group). Because of problems in recruiting patients with severe oesophagitis, an evaluation was carried out after inclusion of the first 49 patients. As the difference observed between the two therapeutic regimens reached the level of significance, the decision was taken to stop the trial.

\section{Results}

\section{ENDOSCOPIC FINDINGS}

The CIS+CIM and PLAC+CIM groups were comparable for age, sex, degree of oesophagitis, and incidence of the main symptom, namely diurnal and nocturnal heartburn (Table 1). The incidence of regurgitation was slightly higher in the PLAC+CIM group but the difference between groups was significant for night time regurgitation only $(p=0.02)$. After six weeks, eight patients in each group were healed and left the trial according to the protocol. One further patient, in the PLAC+CIM group, dropped out because of severe deterioration necessitating hospitalisation.

The global assessment of healing after the first six weeks of treatment indicated that the initial effects of the two treatments were nearly comparable: eight patients in both groups were healed, and slightly more patients in the CIS +CIM group (eight $v$ four in the PLAC+CIM group) were improved. At the

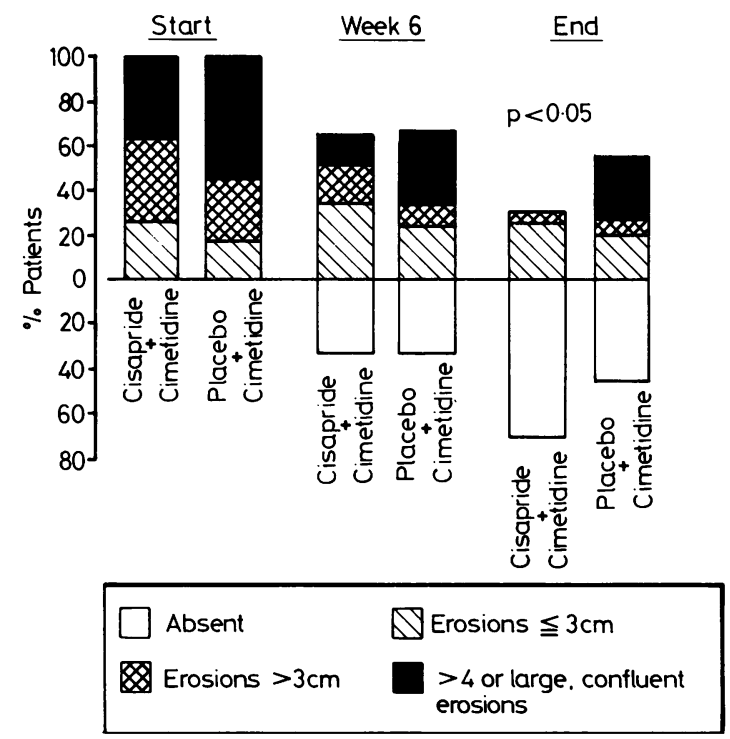

Fig. 1 Severity of oesophageal erosions at the start, after six weeks, and at the end of treatment (week 6 or 12).

end of treatment, 16 patients in the CIS+CIM group were healed, and the remaining seven were improved; in the PLAC+CIM group, 11 patients were healed and three improved. In 10 patients, all in the PLAC+CIM group, the aspect of the mucosa was not substantially modified as compared with the pretreatment condition; the intergroup difference was significant $(p=0.025)$.

The changes in erosion ratings are shown in Figure 1. All patients had erosions at the beginning of the trial. At the end of treatment (week 6 or 12), 16 patients in the CIS+CIM group had no erosions versus 11 in the PLAC+CIM group; in the latter group, six patients still had large lesions (score 3 ).

The changes in severity of ulceration, friability, and exudation are summarised in Table 3. Presence

Table 3 Changes in severity ratings for endoscopic signs of oesophagitis

\begin{tabular}{|c|c|c|c|c|c|c|c|c|c|c|c|c|c|}
\hline & \multirow[b]{2}{*}{$n$} & \multicolumn{4}{|c|}{ Exudation } & \multicolumn{4}{|c|}{ Friability } & \multicolumn{4}{|c|}{ Ulceration } \\
\hline & & 0 & 1 & 2 & 3 & 0 & 1 & 2 & 3 & 0 & 1 & 2 & 3 \\
\hline \multicolumn{14}{|l|}{ Start } \\
\hline $\mathrm{CIS}+\mathrm{CIM}$ & 23 & 4 & 10 & 8 & 1 & 17 & 3 & 3 & 0 & 20 & 2 & 0 & 1 \\
\hline PLAC+CIM & 24 & 7 & 8 & 5 & 4 & 17 & 3 & 3 & 1 & 20 & 2 & 2 & 0 \\
\hline \multicolumn{14}{|l|}{ Week 6} \\
\hline CIS+CIM & 23 & 17 & 2 & 4 & 0 & 20 & 3 & 0 & 0 & 21 & 2 & 0 & 0 \\
\hline PLAC +CIM & 24 & 16 & 5 & 3 & 0 & 22 & 1 & 0 & 1 & 23 & 0 & 1 & 0 \\
\hline \multicolumn{14}{|l|}{ End } \\
\hline $\mathrm{CIS}+\mathrm{CIM}$ & 23 & 19 & 1 & 3 & 0 & 22 & 1 & $\mathbf{0}$ & 0 & 22 & 1 & $\mathbf{0}$ & 0 \\
\hline PLAC +CIM & 24 & 17 & 5 & 2 & 0 & 23 & 0 & 1 & 0 & 23 & 0 & 1 & 0 \\
\hline
\end{tabular}




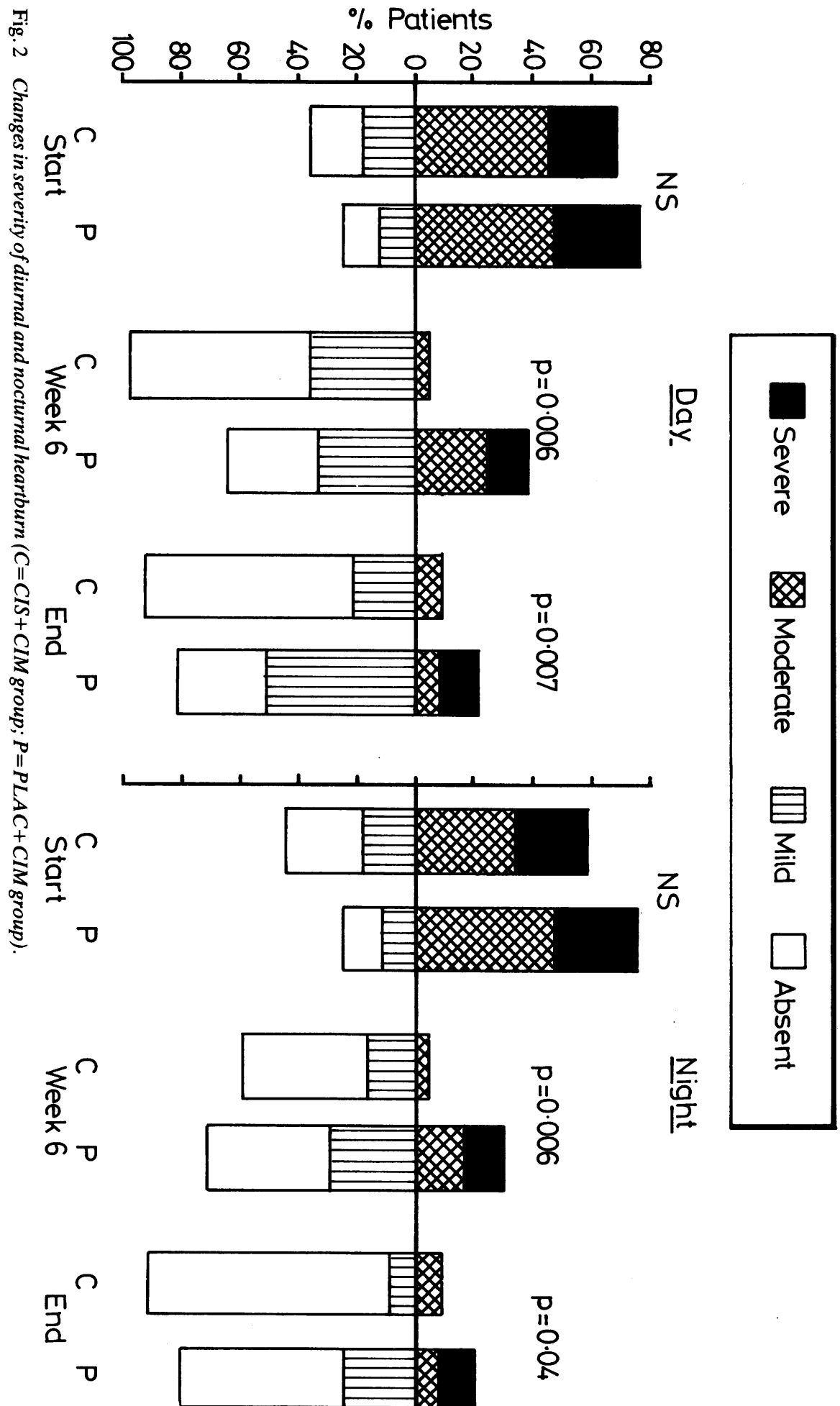


of exudation was significantly $(\mathrm{p}<0 \cdot 01)$ reduced in both groups: from $83 \%$ (CIS+CIM) and $71 \%$ (PLAC+CIM) at the start, to $17 \%$ and $29 \%$, respectively, at the end of treatment (week 6 or 12). The intergroup difference was not significant. Friability and ulceration were initially observed in less than one-third of the patients but in only one patient from each group upon completion of the trial.

\section{CLINICAL ASSESSMENTS}

Changes in severity of the main symptom, diurnal and nocturnal heartburn, are given in Figure 2. After six weeks and at the end of treatment, the symptom severity in both groups was significantly $(p<0.01)$ lower than at the start. As compared with placebo, however, cisapride significantly enhanced the effect of cimetidine (Fig. 2).

The global evaluation of treatment at its end (weeks 6 or 12) is presented in Figure 3. The investigators rated the result excellent or good in $87 \%$ of the patients in the CIS + CIM group, against $64 \%$ of the patients in the PLAC+CIM group $(p<0 \cdot 05)$. The assessment by the patients yielded similar results in favour of combined therapy.

DIARIES

Fifteen patients in the CIS +CIM group and 13 in the PLAC+CIM group completed their diaries in the first six week treatment period; nine and 10 patients, respectively, did so during weeks 6 to 12 . Ridit analysis of the changes in the cluster of reflux symptoms showed a significant $(\mathrm{p}>0.001)$ improvement in both groups. Maalox ${ }^{\circledR}$ consumption was lower in the CIS+CIM group than in the PLAC+ CIM group: the mean weekly number of tablets
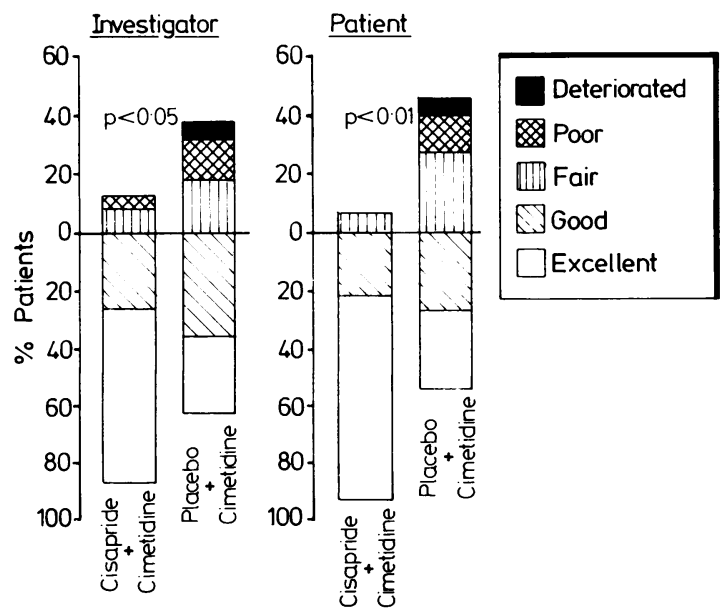

Fig. 3 Global clinical evaluation by investigator and patients at the end of treatment (week 6 or 12).
Table 4 Analysis of variance on ridits calculated from the patients' diaries

\begin{tabular}{|c|c|c|c|c|c|}
\hline Sources of variation & $d f^{*}$ & $\begin{array}{l}\text { Sum of } \\
\text { squares }\end{array}$ & $\%+$ & $\begin{array}{l}\text { Mean } \\
\text { square }\end{array}$ & $F$-value p-value \\
\hline Model & 50 & $7 \cdot 2040$ & & $0 \cdot 1441$ & $17 \cdot 57<0 .(0) 1$ \\
\hline Medication groups & 1 & $1 \cdot 1271$ & $13 \cdot 6$ & $1 \cdot 1271$ & $137.42<0.001$ \\
\hline Time & 11 & $1 \cdot 0047$ & $6 \cdot 2$ & 0.0913 & $11 \cdot 14<0 \cdot 001$ \\
\hline $\begin{array}{l}\text { Patients nested in } \\
\text { medication groups }\end{array}$ & 27 & $5 \cdot 3109$ & $59 \cdot()$ & $0 \cdot 1967$ & $23.98<0 .(001$ \\
\hline Medication X time & 11 & $0 \cdot 0495$ & $0 \cdot 5$ & $0 \cdot 0045$ & $0.55 \mathrm{NS}$ \\
\hline Error & 229 & $1 \cdot 8782$ & $20 \cdot 7$ & 0.0082 & \\
\hline Total & 279 & $9 \cdot 0822$ & $100 \cdot 0$ & & \\
\hline
\end{tabular}

*degrees of freedom; $\uparrow \%$ of explained variation.

taken was, respectively, 3.7 and 11.9 (weeks $1-3$; each week $p \leq 0.05$ ), $2 \cdot 8$ and 8.9 (weeks 4-6; $\mathrm{p} \leq 0.03$ ); 4.6 and 6.5 (weeks $7-9 ; \mathrm{NS}$ ), 3.9 and 5.4 (weeks 10-12; NS). Analysis of variance done on the overall ridits, combining Maalox ${ }^{\circledR}$ consumption and frequency of daytime and night time heartburn and regurgitation, indicated that a highly significant part of the variance could be explained by the model used. This model takes into account the medication groups, duration of treatment, patients allocated to the medication groups, and interaction between medication groups and duration of treatment (Table 4). Medication and patients were highly significant sources of variation $(13.6 \%$ and $59 \%)$. Treatment duration contributed less to variance. Interaction between the type of medication and the duration of treatment did not explain a significant proportion of the variance. Only $20.7 \%$ of the variation remained unexplained.

\section{SIDE EFFECTS}

Data on 24 patients in each group were included in the side effects analysis. Two in the CIS + CIM group and 3 in the PLAC+CIM group had adverse experiences. In the former group, one patient reported mild evening nervousness, probably not drug related as it persisted after the end of the study while another experienced, frequent bowel movements. In the latter group, three patients had diarrhoea; in one of these patients, diarrhoea was associated with anal pruritus; this patient also experienced severe vomiting during the third treatment week.

\section{Discussion}

During the past decade, new antisecretory drugs have improved possibilities for the treatment of chronic reflux disease; as an alternative to antireflux surgery, suppression of gastric acid secretion has become very popular. Several studies have indeed 
shown that both cimetidine and ranitidine significantly alleviate symptoms and improve lesions. ${ }^{18-21}$ Placebo controlled studies have also indicated that motility drugs significantly reduce reflux symptoms (metoclopramide) ${ }^{22}$ and lesions (bethanechol). ${ }^{23}$ Good evidence for the usefulness of cisapride was also obtained when this drug was compared with placebo in the treatment of patients with gastrooesophageal reflux disease. ${ }^{10}$ Furthermore, in one study cisapride appeared to be at least as effective as ranitidine $150 \mathrm{mg} \mathrm{bid}^{24}$ in the healing of oesophagitis.

Few studies have addressed the usefulness of treatments combining $\mathrm{H}_{2}$-blockers and prokinetic drugs. In the study by Temple et al, ${ }^{12}$ cimetidine+ metoclopramide was not more efficacious than cimetidine alone. The conclusions of this trial have been questioned, however, because of the high dropout rate. Liebermann and Keeffe recently reported the results of a similar comparison done in patients with cimetidine resistant reflux oesophagitis." The combined therapeutic effect of cimetidine (300 $\mathrm{mg}$ qid) and metoclopramide $(10 \mathrm{mg}$ qid) was compared with that of cimetidine and placebo. A significant benefit in healing of mucosal lesions and a reduction in symptoms was observed in refractory patients receiving combined therapy. The high incidence of side effects with metoclopramide may have biased the study, however, ${ }^{5}$ as the investigators might have been aware of which patients were taking metoclopramide rather than placebo.

The results of the present trial indicate that patients with erosive oesophagitis showed better symptomatic and endoscopic response to cisapride+ cimetidine therapy than to cimetidine administration alone. The overall endoscopic healing rates were $70 \%$ and $46 \%$, and marked improvement was noted in another $30 \%$ and $13 \%$ of the patient in the CIS+CIM and PLAC+CIM groups, respectively. The superiority of the combined therapy became particularly evident between the sixth and 12th week of treatment in patients who failed to fully respond during the first six week period. These results differ from those obtained by Wienbeck ${ }^{25}$ who failed to show any significant difference between ranitidine+ cisapride and ranitidine alone. This apparent difference, however, may be because of either the lower dosage of cisapride used in the latter study $(20 \mathrm{mg}$ instead of $40 \mathrm{mg}$ in our trial) and/or the more pronounced efficacy of ranitidine in controlling acid reflux (compared with cimetidine) as suggested by our previous findings with prolonged oesophageal pH measurements. ${ }^{26}$

In the present study cisapride was well tolerated and no serious side effects were observed. This finding contrasts with the poor tolerance of metoclopramide generally reported, ${ }^{4}$ at least at the high doses required for the treatment of reflux oesophagitis symptoms. The pharmacological data and the experience accumulated with cisapride suggest that it is a safe drug which can be prescribed without any other precaution than those given concerning any new medication; cisapride has also proved satisfactory and safe in children. ${ }^{27}$

If the present findings can be confirmed, cisapride will prove to be a valuable adjunct to cimetidine in the treatment of severe reflux oesophagitis.

The authors thank T Aerts and B Fraitag for editorial assistance, F Shapiro for assistance with the English, and P Hassan for secretarial assistance.

A part of this work has been published in an abstract form (Gastroenterology 1987; 92: 1400).

\section{References}

1 De Meester TR, Johnson LF, Joseph GJ, Toscano MS, Hall AX, Skinner DB. Patterns of gastroesophageal reflux in health and disease. Ann Surg 1976; 184: 459-70.

2 Dodds WJ, Hogan WJ, Helm JF, Dent J. Pathogenesis of reflux oesophagitis. Gastroenterology 1981; 81: 376-94.

3 Castell DO. Introduction to pathophysiology of gastroesophageal reflux. In: Castell DO, Wu WC, Ott DJ, eds. Gastroesophageal reflux disease. New York: Futura, 1985: 3-9.

4 Richter JE. Gastroesophageal reflux disease: a review of medical therapy. In: Castell DO, Wu WC, Ott DJ, eds. Gastroesophageal reflux disease. New York: Futura, 1985: 221-41.

5 Castell DO. Medical therapy for reflux esophagitis: 1986 and beyond. Ann Intern Med 1986; 104: 112-4.

6 Reyntjens A, Verlinden M, Aerts T. Development and clinical use of the new gastrointestinal prokinetic drug cisapride (R 51 619). Drug Dev Res 1986; 8: 251-65.

7 Jian R, Ducrot F, Piedeloup C, Mary JY, Najean Y, Bernier JJ. Measurement of gastric emptying in dyspeptic patients: effect of a new gastrokinetic agent (cisapride). Gut 1985; 26: 352-8.

8 Müller-Lissner SA, Fraass C. Chronic oral treatment with cisapride decreases high bile salt reflux rates. $\mathrm{Am} \mathrm{J}$ Gastroenterol 1986; 81: 354-7.

9 Reyntjens A, Verlinden M, De Coster R, et al. Clinical pharmacological evidence for cisapride's lack of antidopaminergic or direct cholinergic properties. Curr Ther Res 1984; 36: 1045-52.

10 Lepoutre L, Vanderlinden I, Bollen G, et al. Controlled study of cisapride in the treatment of grade II and III oesophagitis [Abstract]. Gastroenterology 1987; 92: 1501 .

11 Liebermann DA, Keeffe EB. Treatment of severe reflux esophagitis with cimetidine and metoclopramide. Ann Intern Med 1986; 104: 21-6.

12 Temple JG, Bradby GV, O'Connor F, et al. Cimetidine and metoclopramide in oesophageal reflux disease. Br Med J 1983; 286: 1863-4. 
13 Savary M, Miller G. L'oesophage. Manuel et atlas d'endoscopie. Solothurn, Switzerland: Gassmann AG, 1977.

14 Siegel S. Nonparametric statistics. New York: McGrawHill, 1956: 312.

15 Bross IDJ. How to use ridit analysis. Biometrics 1958; 14: 18-38.

16 Sokal RR, Rohlf FJ. Biometry. San Francisco: W H Freeman, 1981: 321

17 SAS. User's Guide: Statistics. Cary, NC: SAS Institute Inc, 1985: 956.

18 Behar J, Brand DL, Brown FC, et al. Cimetidine in the treatment of symptomatic gastroesophageal reflux: a double-blind controlled trial. Gastroenterology 1978; 74: 441-8.

19 Fiasse R, Hanin C, Lepot A, Deschamps C, Lamy F, Dive C. Controlled trial of cimetidine in reflux esophagitis. Dig Dis Sci 1980; 25: 750-5.

20 Wesdorp E, Bartelsman J, Pape K, Dekker W, Tijtgat GN. Oral cimetidine in reflux esophagitis: a doubleblind controlled trial. Gastroenterology 1978; 74: 821-4.

21 Wesdorp ICE, Dekker W, Klinkenberg-Knol EC. Treatment of reflux oesophagitis with ranitidine. Gut 1983; 24: 921-4.
22 McCallum RW, Ippoliti AF, Cooney C, Sturdevant RAL. A controlled trial of metoclopramide in symptomatic gastroesophageal reflux. N Engl J Med 1977; 296: 354-7.

23 Thanik KD, Chey WY, Shah AS, Guttierez JG. Reflux esophagitis: effect of oral bethanechol on symptoms and endoscopic findings. Ann Intern Med 1980; 93: 805-8.

24 Janisch HD. A double-blind multicenter trial to compare the efficacy of cisapride (CIS) and ranitidine (RAN) in the acute treatment of gastroesophageal reflux disease (GERD) [Abstract]. Gastroenterology 1986; 90: 1475 .

25 Wienbeck $M$. Therapeutic effect of cisapride added on to ranitidine in patients with reflux esophagitis [Abstract]. Dig Dis Sci 1986; 31: suppl: 27S.

26 Desechalliers JP, Galmiche JP, Touchais JY, Denis P, Colin R. Ranitidine, cimetidine, antacids and gastro-oesophageal reflux: Results of a 20-hour oesophageal pH study. Int J Clin Pharmacol Res 1984; 4: 217-22.

27 Forget PP, Saye P. Effect of cisapride on gastrooesophageal reflux in children with chronic bronchopulmonary disease (CBPD). A pH-metric study [Abstract]. Dig Dis Sci 1986; 31: suppl: 28 S. 